\title{
INVESTIGATION OF RADIOSENSITIVITY OF GAMMA IRRADIATED ISONIAZID ANTIBIOTIC THROUGH EPR SPECTROSCOPY
}

\author{
Kerem SÜTÇÜ1,*, Yunus Emre OSMANOĞLU², Firat AKBALIK ${ }^{3}$ \\ ${ }^{\mathbf{1}}$ Department of Science, Faculty of Education, Dicle University, 21280 Diyarbakır, TURKEY \\ ${ }^{2}$ Department of Oncology, Faculty of Medicine, Dicle University, 21280 Diyarbakır, TURKEY \\ ${ }^{3}$ Department of Physics, Graduate School of Natural and Applied Science, Dicle University, 21280 Diyarbakır, TURKEY
}

\begin{abstract}
Dosimetric properties of gamma irradiated Isoniazid (IS) were investigated through Electron Paramagnetic Resonance (EPR) spectroscopy. While unirradiated IS presented no EPR signal, irradiated IS exhibited a significant EPR spectrum at room temperature. Some EPR parameters of obtained experimental spectrum were calculated. In order to describe the variation of EPR signal intensity with absorbed radiaiton dose, several mathematical equations were tried. It has been determined that the best fit of IS sample is with polinomial function $\left(R^{2}=0.9675\right)$. Moreover time dependency of the intensity of the EPR signal of the irradiated sample was analysed to study the stability of the free radicals.
\end{abstract}

Keywords: EPR, Gamma irradiation, antibiotic

\section{INTRODUCTION}

In the changing and developing world conditions, the radiation energy is benefited from for different purposes. While aiming to use the radiation for the benefit of humans, to preserve the public health for now and future is the initial condition [1]. In the early 1970s, radiation applications at high doses were applied on drugs. This situation usually caused undesired colour, odour, viscosity and chemical changes. In the light of the developments in the sterilisation processes, $10^{-6} \mathrm{SAL}$ (Sterility Assurance Level) can be attained now by applying a lower radiation dose [2].

Nowadays, sterilisation by irradiation method is used to increase the hygienic quality of the drugs and food [3-5]. Due to the very high penetration properties of gamma radiation, sterilisation by irradiation method can be applied to the samples even after the packaging, and also it does not leave any chemical residue [6]. Furthermore, the sample sterilised with gamma does not obtain radioactive characteristics, and an increase in its temperature does not occur [7]. Besides these advantages, gamma irradiation also has some disadvantages due to their high energies. The first of these is that they create new radiolytic products in the product to which gamma radiation is applied, and the second one is that irradiation regulations differ from country to country [8]. For this reason, the consumers would like to know whether the products they consume have been exposed to radiation; if they have, how much dose has been applied [9]. Within this context, determining the radiosensitivity of the drugs is gaining considerable importance. EPR spectroscopy is accepted to be one of the preeminent methods in determining the radiosensitivity of the drugs and food samples [10-11].

*Corresponding Author:_ksutcu@dicle.edu.tr 
The radiosensitivity of many drugs and food samples was examined by using EPR spectroscopy. In their study in which Ghelawi et al. examined the radiosensitivity of the irradiated date stones; it was reported that $25 \%$ of the agricultural products in the third world countries would spoil before they reached the markets [12]. In the EPR examination of sulphathiazole sample irradiated with gamma, which is an antibacterial drug, $\mathrm{g}=2.0045$ and the $\Delta \mathrm{H}$ value was calculated as $5.2 \mathrm{mT}$ [13]. Basly et al. examined the decaying of EPR signal intensity of the cefoperazone sample irradiated with gamma in time. It was calculated that the $77 \%$ of the radicals which formed after 26 days of waiting; and $89 \%$ of them decayed after 57 days. It was determined that the EPR signals which formed after the irradiation could only be detected until the $140^{\text {th }}$ day maximum [14].

\section{EXPERIMENTAL}

Pulverised IS was purchased from the companies producing chemical compounds with the support of Dicle University Scientific Research Projects (DUBAP) coordination. The irradiation processes of the samples to which any kind of operation was not applied after they had been purchased, were carried out (in the dose range of 0-15 kGy) in the Sarayköy facility of the Turkish Atomic Energy Authority (TAEK) at room temperature by using ${ }^{60} \mathrm{Co}$ gamma ray source. As for spectrum absorption processes; a Varian Line Century Series E109 X-band EPR spectrometer located in the EPR laboratory of Ondokuz Mayis University was used. The spectrums of the powder samples were recorded at room temperature by putting them into a quartz tube with $4-5 \mathrm{~mm}$ diameter. The corrections of the slips of the spectrometer in the microwave frequency were corrected by taking the $g$ value $(g=2.0036)$ of DPPH (Diphenylpicrylhydrazyl) radical as a reference.

\section{RESULTS AND DISCUSSION}

Drugs containing isoniazid, rifampicin, pyrazinamide and ethambutol hydrochloride are used in the treatment of tuberculosis which is a contiguous disease. The most used one among these is the isoniazid sample [15]. Some chemical properties of IS sample are given in Table 1.

Table 1. Formula, molecular weight and chemical structure of IS

\begin{tabular}{l|c|c}
\hline \multicolumn{1}{c|}{ Formula } & $\begin{array}{c}\text { Molecular } \\
\text { weight }\end{array}$ & Chemical structure \\
\hline $\mathrm{C}_{6} \mathrm{H}_{7} \mathrm{~N}_{3} \mathrm{O}$ & $137.14 \mathrm{~g} / \mathrm{mol}$ &
\end{tabular}

The EPR spectra of the IS sample non-irradiated and irradiated at different doses are shown in Figure 1. That any EPR signal is not observed in the non-irradiated sample and, on the contrary, that explicit EPR signals are obtained in the irradiated sample show that irradiation creates free radicals in the IS sample. Moreover, that the increase in the amount of radiation dose applied to the sample increases the peak-to-peak distance of the EPR spectrum signal reveals that it also increases the number of the radicals created in the sample after the irradiation. 


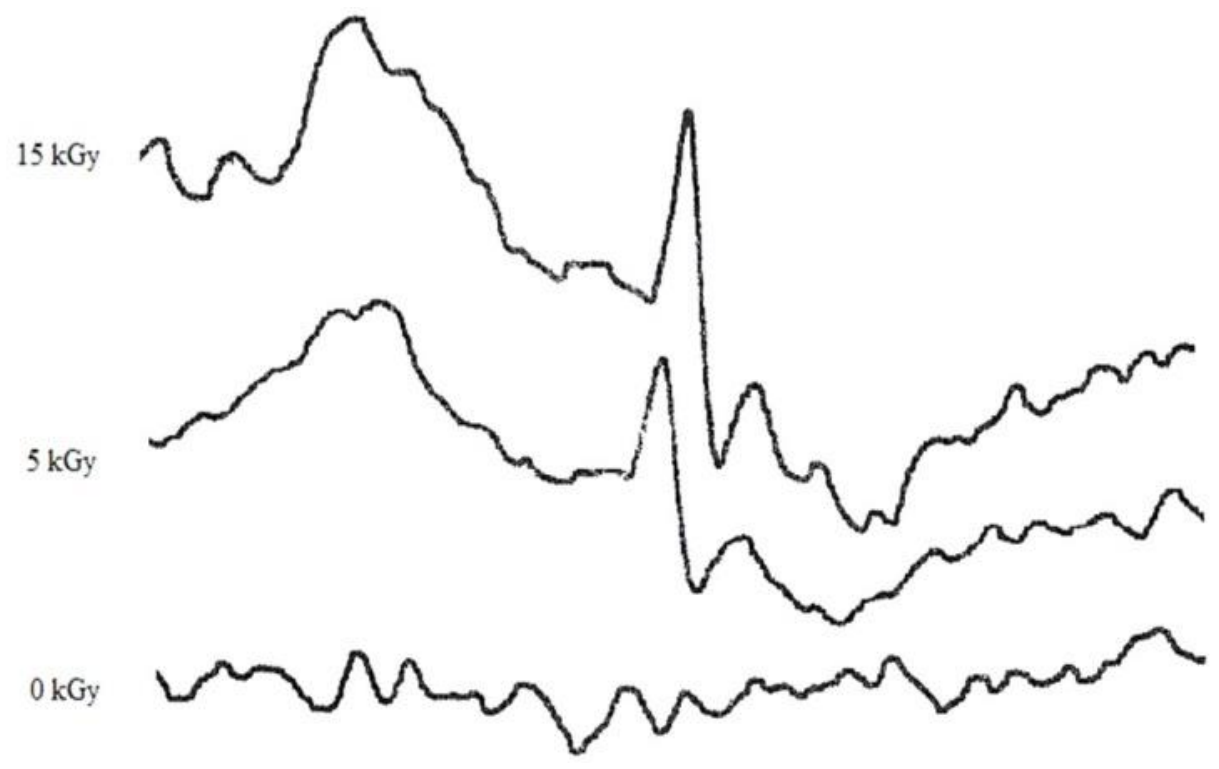

Figure 1. EPR spectra of $\gamma$-irradiated IS at different absorbed doses

The literature compatible $g$ value of the EPR spectrum which was dispersed in a magnetic field area with $5 \mathrm{mT}$ value of the pulverised IS sample irradiated $15 \mathrm{kGy}$ at room temperature was calculated to be $2.0016[16,17]$. It was determined that the increasing radiation dose did not cause any significant change in the shape of EPR spectrum taken at room temperature, and also it did not change the $g$ value either. It was observed that the resonance peak in the spectrum became more evident as the irradiation dose approached $15 \mathrm{kGy}$.

In order to obtain the dose-response curve of the IS sample, samples irradiated with gamma at 1, 5, 10, 12 and $15 \mathrm{kGy}$ dose values were used. While the squares shown in Figure 2 define the experimental results, the curve defines the mathematical equation which is the closest to the experimental results.

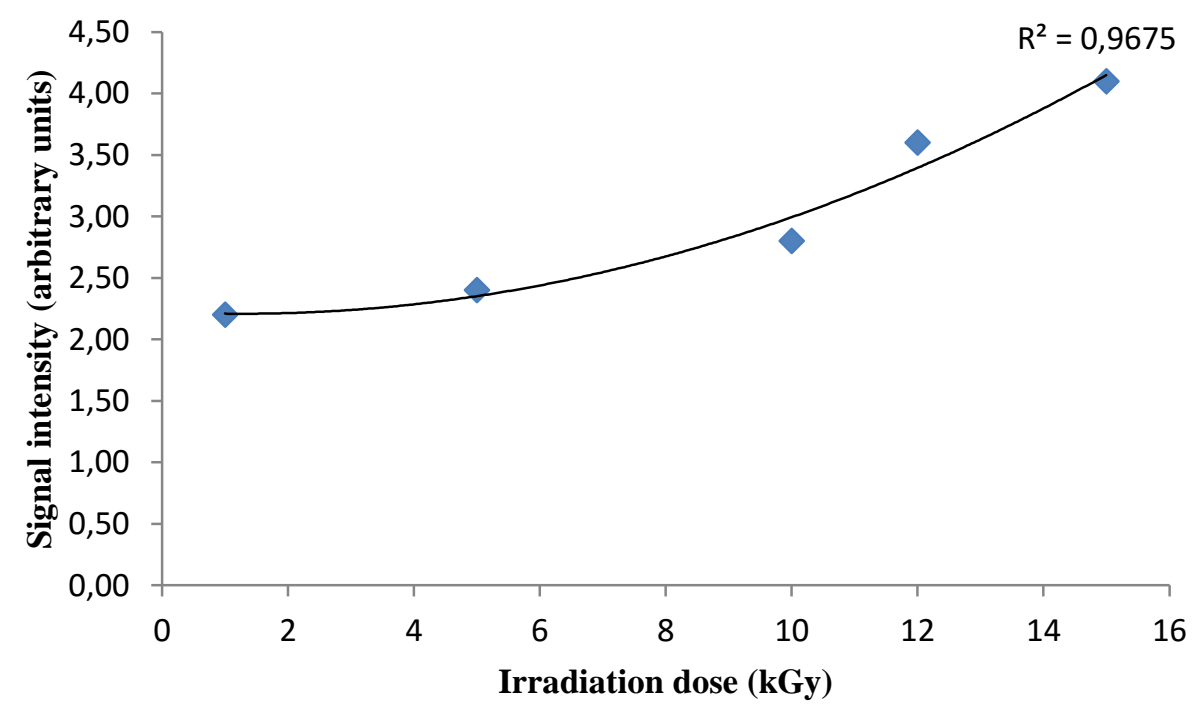

Figure 2. Dose-response curve of IS

The selection of the mathematical expression which defines the dose-response curve is quite important in determining the dose. There is not a single analytic method for this selection. It was attempted to determine the mathematical functions which were the closest to the experimental results obtained for 
the IS sample. It was observed that the dose-response curve of the sample was quite compatible with polynomial, exponential and linear functions. The values of these three functions are given in the Table 2. When the table was examined, it was determined that the obtained curve demonstrated the best compatibility with $\mathrm{I}=a \mathrm{D}^{2}+b \mathrm{D}+c$ function. Here; I indicates the signal intensity measured from the EPR spectrum of the sample, and D indicates the amount of radiation dose applied to the sample. Furthermore, it is seen that the smallest value of $\mathrm{R}^{2}$ is 0.8893 for the selected functions.

Table 2. Mathematical functions calculated for dose-response curve of $\gamma$-irradiated IS

\begin{tabular}{l|c|c}
\hline $\mathrm{I}=a \mathrm{D}^{2}+b \mathrm{D}+c$ & $a=0.0103$ & $\mathrm{R}^{2}=0.9675$ \\
& $b=-0.0263$ & \\
& $c=2.2253$ & \\
\hline $\mathrm{I}=e \mathrm{D}^{f}$ & $e=1.9872$ & $\mathrm{R}^{2}=0.9237$ \\
& $f=0.0454$ & $\mathrm{R}^{2}=0.8893$ \\
\hline $\mathrm{I}=g \mathrm{D}+h$ & $g=0.1361$ & \\
\hline
\end{tabular}

The signal obtained through irradiation in the irradiated drugs has to be testable during the shelf life of the sample [7]. After the irradiation of the IS sample with gamma, EPR spectra at room temperature were recorded within a period of 196 days at definite intervals. While any distinct change was not observed in the shape and $g$ value of the signal in the obtained spectra, a decrease in the intensity of the signal was detected. During this process, the sample was preserved hermetical in a dark environment and at room temperature.

It was attempted to determine the decaying of the free radicals formed in $15 \mathrm{kGy}$ irradiated IS sample which was preserved as described above. The curve of the change in signal intensity of the irradiated sample within 200 days is shown in Figure 3. The data shown with squares in figure demonstrate the experimental results. While the signal intensity drops to $78 \%$ at the end of the $124^{\text {th }}$ day, $41 \%$ of loss occurred at the end of 196 days. These data, even at the end of 196 days of the IS sample, show that whether it is irradiated or not can be determined when the EPR spectroscopy method is employed.

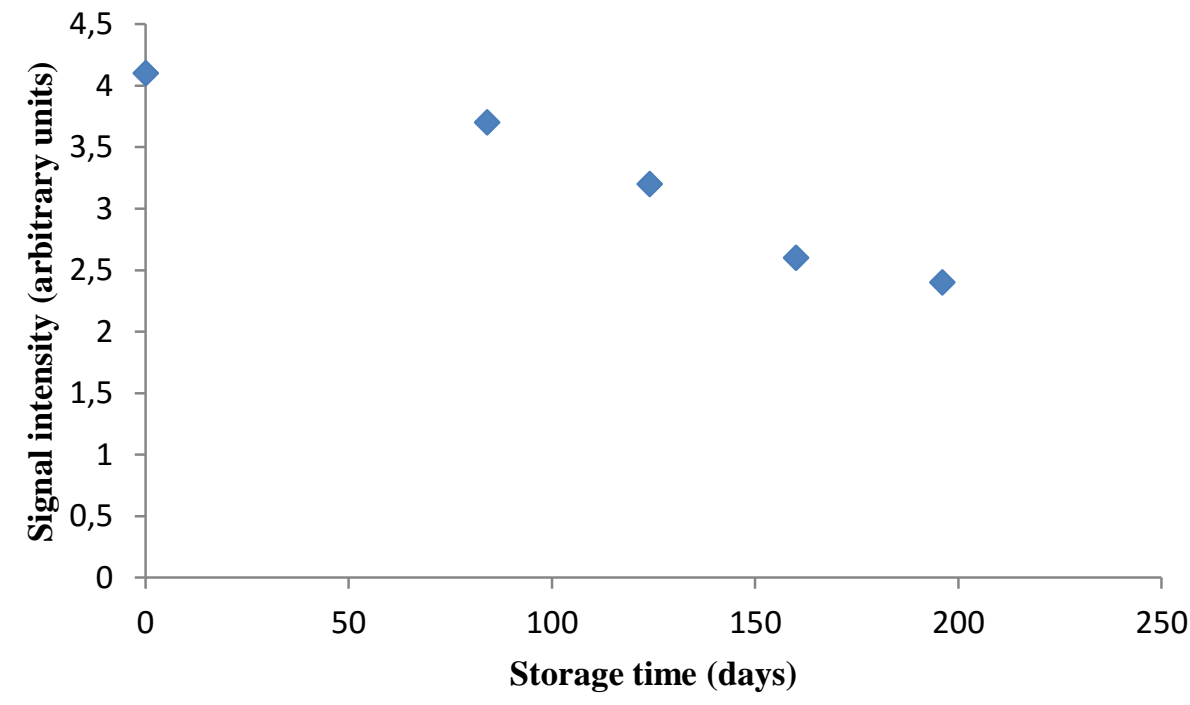

Figure 3. EPR signal intensity of IS irradiated at a dose of $15 \mathrm{kGy}$ as a function of time 


\section{CONCLUSIONS}

That any signal is not observed in the EPR spectrum obtained from the non-irradiated IS sample yet recording significant signals in the spectra obtained after the radiation exposure of the sample clearly demonstrates that free radicals are formed in the IS sample after the irradiation. When the doseresponse curve of the sample is examined, calculation of the mathematical equations with correlation values that are very close to the experimental results enables us to calculate the value of the signal intensity of IS sample irradiated at any dose value with a very close probability. Moreover, having only $50 \%$ loss in the irradiated IS sample at the end of approximately 200 days shows that stable radicals are formed in the sample after the irradiation. This situation reveals that sterilisation of the IS sample with radiation is not suitable.

\section{ACKNOWLEDGMENTS}

This study was funded by Grant No. 12-FF-09 of Research Fund of Dicle University (DUBAP)

\section{REFERENCES}

[1] Coşkun M, Coşkun M. Biological dosimeter and related developments. Cerrahpaşa J Med 2003; 34: 207-218.

[2] Basly JP, Bernard M. Radiosterilization dosimetry by ESR spectroscopy - ritodrine hydrochloride and comparison with other sympathomimetics. Int J Pharma 1997; 149: 85-91.

[3] Diehl JF. Food irradiation—past, present and future. Radia. Phys Chem 2002; 63: 211-215.

[4] Bhat R. Sridhar KR. Influence of ionizing radiation and conventional food processing treatments on the status of free radicals in lotus seeds: An ESR study. J Food Comp Anal 2011; 24: 563-567.

[5] Aleksieva K, Lagunov KO, Dimov K, Yordanov ND. EPR study on non- and gamma-irradiated herbal pills. Radiat Phys Chem 2011; 80: 767-770.

[6] Ambroz HB, Kornacka EM, Marciniec B, Przybytniak GJ. Radical decay in irradiated drugs: Flutamide, ifosfamide. Radioanalytical Nuc Chem 2002; 254: 293-298.

[7] Basly JP, Basly I, Bernard M. Electron spin resonance detection of radiosterilization of pharmaceuticals: application to four nitrofurans. The Analyst 1998; 123: 1753-1756.

[8] Basly JP, Longy I, Bernard M. Influence of radiation treatment on theodrenaline. Int J Pharma 1997; 152: 201-206.

[9] Delincee H, Analytical methods to identify irradiated food- a review. Radiat Phys Chem 2002; 63: 455-458.

[10] Karakirova Y, Yordanov ND. Mannitol as a radiation sensitive material for electron paramagnetic resonance dosimetry. Bulgarian Chem Commun 2015; 47: 144-148.

[11] Ambroz HB, Kornacka EM, Marciniec B, Ogrodowczyk M, Przybytniak GK. EPR study of free radicals in some drugs $\gamma$-irradiated in the solid state. Radiat Phys Chem 2000; 58: 357-366.

[12] Ghelawi MA, Moore JS, Bisby RH, Dodd NJF. Estimation of absorbed dose in irradiated dates (Phoenix dactylifera L.). Test of ESR response function by a weighted linear least-squares regression analysis. Radiat Phys Chem 2001; 60: 143-147. 
[13] Çolak Ş, Korkmaz M. Spectroscopic features of radiolytic intermediates induced in gamma irradiated sulfatiazole: an ESR study. Int J Pharma 2004; 285: 1-11.

[14] Basly JP, Basly I, Bernard M. ESR spectroscopy applied to the study of pharmaceuticals radiosterylization: cefoperazone J Pharm Biomed Anal 1998; 17: 871-875.

[15] Gowthaman, NSK, Kesavan S, Abraham John S. Monitoring isoniazid level in human fluids in the presence of theophylline using gold@platinum core@shell nanoparticles modifiedglassy carbon electrode. Sensors and Actuators B Chem 2016; 230: 157-166.

[16] Basly JP, Basly I, Bernard M. Radiation induced effects on cephalosporins: an ESR study. Int J Radiat Biol 1999; 75: 259-263.

[17] Gibella M, Crucq AS, Tilquin B, Stocker P, Lesgards G, Raffi J. Electron spin resonance studies of some irradiated pharmaceuticals. Radiat Phys Chem 2000; 58: 69-76. 